\title{
IMPROVING THE QUALITY OF SMALL PIECES MADE BY RAPID PROTOTYPING
}

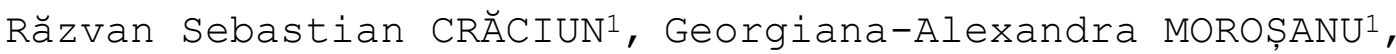 \\ Virgil Gabriel TEODOR ${ }^{1}$
}

\begin{abstract}
${ }^{1}$ Department of Manufacturing Engineering, "Dunărea de Jos” University of Galați, România email: alexandra.costin@ugal.ro
\end{abstract}

\begin{abstract}
Rapid Prototyping is the rapid fabrication of a part, model, or physical assembly that was designed using any design software (Autodesk Inventor Professional in this case), which is a CAD (Computer-Aided Design) application that helps in the creation of a digital prototype. The creation of the part, model, or assembly is usually completed using the manufacture of additives or more commonly known as $3 D$ printing. The paper presents a $3 D$ design, $3 D$ printing, and verifying the actual dimensions of the printed ,washer". The purpose of this paper is to verify that printing errors are controllable and can be reduced. The paper contains and explains all the mandatory steps required to do this experiment and the laboratory equipment that was used to do this.
\end{abstract}

KEYWORDS: rapid prototyping, samples, 3D printing, diameter, thickness.

\section{INTRODUCTION}

3D printing or additive manufacturing is a process of making three-dimensional solid objects by adding layer after layer. Physical objects are produced using data from a digital model, a 3D model, or other sources such as an AMF (Additive Manufacturing File) [1] file type.

Rapid Prototyping [2], is the rapid fabrication of a physical part, a model, or a physical assembly, using a CAD (Computer-Aided Design) project. The creation of the part, model, or assembly is usually completed using the manufacture of additives or more commonly known as 3D printing.

In case the design fits closely with the proposed finished product, it can be said that the prototype has a high fidelity rate, as opposed to a low fidelity prototype, where there is a significant difference between the prototype and the final product.

Rapid Prototyping (RP) includes a variety of manufacturing technologies, although the most used is the manufacture of layered additives. However, other technologies used for RP include high speed printing, casting, molding and extrusion.

While additive manufacturing is the most common RP process, other more conventional processes can also be used to create prototypes.

Product designers use this process to quickly manufacture prototype parts. This can help visualize, design, and development of the manufacturing process before starting mass production.
Initially, rapid prototyping was used to create scale parts and models for the automotive industry, although it has since been taken over by a wide range of applications in several industries, such as medical and aerospace.

There are a number of advantages to rapid prototyping, such as the ability to get a more complete picture of how a product will look or perform in the early stages of the design and manufacturing cycle, allowing changes or improvements to be implemented earlier in the process. The time required can vary from a few minutes to a number of days, depending on the methods used.

Rapid Prototyping is a very effective way to protect products because it is an automated process, requiring less staff to operate. This process is also extremely precise, being able to use computer-aided design (CAD) to help reduce material waste and does not require special tools for prototyping each new product. The ability to identify potential problems and act quickly also reduces the risk of costly errors during the manufacturing phase.

Rapid prototyping helps designers introduce new concepts to board members, customers, or investors so that they can understand and approve an improvement of a product or make a new product. This visualization can also allow designers to get feedback from customers based on an actual physical product, rather than a concept.

Because rapid prototyping is an iterative process, it allows customer requirements to be 
incorporated into cost-effective projects. The process reduces the need for custom products to be designed from scratch while providing greater choice and flexibility for customers.

\section{EQUIPMENT AND MATERIALS USED}

\section{$3 D$ printer}

Ultimaker 3 Extended [3], figure 1, is the most reliable dual-extrusion $3 \mathrm{D}$ printer available.

Capable of carrying out complex projects and improved 3D printing performance, thanks to its unique automatic nozzle lifting system, professional combinations of building and support materials, and interchangeable printing cores.

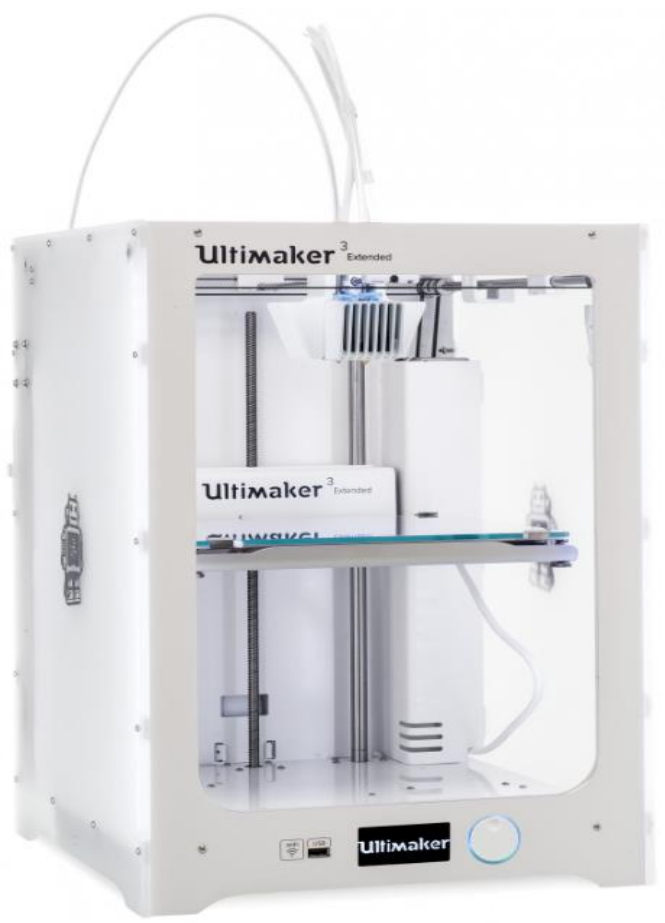

Figure 1. Ultimaker 3 Extended [4]

Thanks to the seamless integration of hardware, software, and materials, Ultimaker 3 Extended enables designers, engineers, and manufacturers to approach the innovation process in a whole new way.

With the possibility of creating complex geometries and obtaining a remarkable design complexity with the most reliable double extrusion on the market.

The main features of the Ultimaker 3 Extended printer are:

- the volume built, $215 \times 215 \times 300 \mathrm{~mm}$;

- layer resolution up to 20 microns for $0.4 \mathrm{~mm}$ nozzle;

- print temperature up to $280^{\circ} \mathrm{C}$;

- double extrusion with a soluble support material;

- interchangeable printing cores;

- heated construction plate with active leveling.

\section{Polylactic Acid (PLA)}

The material used for printing is polylactic acid (PLA), a thermoplastic polyester [5].

Made from renewable resources such as corn starch, tapioca roots, or sugar cane, it is a very easyto-use material. One of the most impressive things about this type of polymer is that it degrades naturally when exposed to the environment (in about 6-24 months).

PLA has the following main advantages in 3D printing: easy to print and available in a wide variety of colors, as well as disadvantages in 3D printing: unsuitable for functional prototypes or objects subjected to high temperatures.

PLA is different from most thermoplastic polymers because it is derived from the renewable resources mentioned above. Most polymeric materials come from the distillation and polymerization of nonrenewable oil reserves. Polymeric materials that are derived from biomass (such as PLA) are known as "bioplastics".

Polylactic acid is biodegradable and has similar characteristics to polypropylene (PP), polyethylene (PE), or polystyrene (PS). It can be produced by existing production equipment (those originally designed and used for the plastics petrochemical industry). This makes it relatively cost effective.

Consequently, PLA has the second largest production volume, the largest of any bioplastic (most commonly referred to as thermoplastic starch).

PLA is classified as a "thermoplastic" polyester, and the name has to do with how the material responds to heat.

Thermoplastic materials become liquid at their melting point $\left(150-160^{\circ} \mathrm{C}\right.$, in the case of PLA).

An important attribute for thermoplastics is that they can be heated to their melting point, cooled, and reheated again without significant degradation.

Instead of burning, thermoplastics such as polylactic acid liquefy, allowing them to be easily injected into molds and then recycled later. On the contrary, thermo-rigid plastics can be heated only once (usually during the injection molding process).

\section{Horizontal Profile Projector}

The measuring device used is a Starrett Optical HE400 profile projector, presented in figure 2, for horizontal profiles, and the control system is QuadraCheck QC200 [6]. 


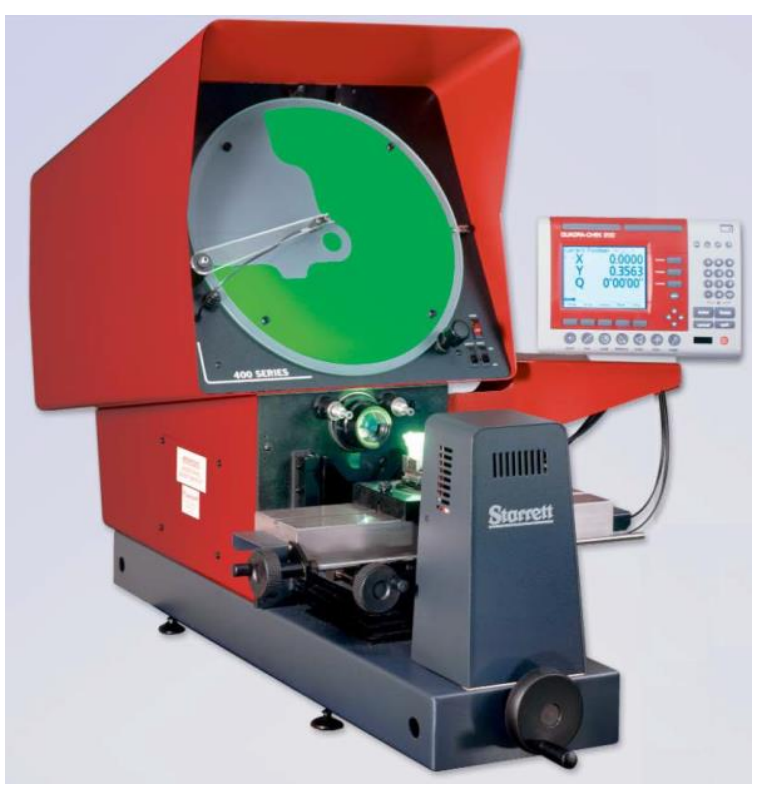

Figure 2. Horizontal Profile Projector, Starrett Optical [7]

The HE400 horizontal optical comparator offers a $400 \mathrm{~mm}$ diameter screen, able of fast movement on the $\mathrm{X}$-axis $(250 \mathrm{~mm})$ and $\mathrm{Y}$-axis $(100 \mathrm{~mm})$, quickchange bayonet mounting lenses, a Q-axis digital protector with angular measurements at resolution and a powerful software control system, known as Quadra-Chek 200.

It is simple to use, with an outstanding capacity and performance to meet an exceptionally wide range of dimensional inspection applications and complex measurement requirements. At the heart of these systems, there are precision optics, excellent lighting and an extremely precise working stage that combine to ensure bright, sharp images and exceptional accuracy.

The horizontal models work well with parts that need to be fixed in a vise or in the center. This model includes the ability to measure 2D geometric features such as: point, line, angle, radius, and diameter.

Specifications:

- stable, complete metal construction;

- screen diameter (inch): 16 ";

- screen diameter (mm): 400;

- $X$ - $Y$ Measuring range (inch): $10 " \mathrm{x} 4 "$;

- $X$ - $Y$ Measuring range (mm): $250 \times 100$;

- focus range (inch): 1.125";

- focus range (mm): 30 ;

- work stage (inch): $18.75^{\prime \prime}$ x $4.75 "$;

- work stage (mm): 475 x 120;

- load capacity with negligible deviation $(\mathrm{kg})$ : 6.8;

- maximum load capacity (kg): 25;

- angular measuring resolution: 1 minute;

- profile lighting: Standard;

- surface lighting: Standard;

- control system / Software: QC100/200, M2.

\section{DESIGNING, PRINTING, AND MEASUREMENT OF PRINTED PARTS}

For designing, printing, and measurement of printed parts, the following steps were taken:

- The digital model: Small "ring" / "washer" shaped specimen was designed in Autodesk AutoCAD 2019, with the following nominal dimensions:

a. inner diameter, $d=\varnothing 20 \mathrm{~mm}$;

b. external diameter, $D=\emptyset 30 \mathrm{~mm}$;

c. thickness, $g=4 \mathrm{~mm}$.

- Model in format *.stl: the drawing was exported in *.stl (stereolithography) so that it can be opened with the program Ultimaker Cura 3.5.1;

- Checking and repairing the model *.stl: using the program Ultimaker Cura 3.5.1, the characteristic printing parameters were introduced, the analyzed ones being: printing speed, $v[\mathrm{~mm} / \mathrm{s}]$, printing temperature, $T\left[{ }^{\circ} \mathrm{C}\right]$ and layer height, $h[\mathrm{~mm}]$, for 3D printing on the 3D printer Ultimaker 3 Extended. 3D printer; the file was saved as *.gcode ( $\mathrm{G}$ code), so that it can be imported into the 3D printer software;

- Preparing the $3 D$ printer: At this stage, the equipment is being prepared for printing; the process requires proper setting and control of the $3 \mathrm{D}$ printer, cleaning the work table and loading the raw material; a routine check of all main print settings and the control panel is also required; when the machine is ready, the $3 \mathrm{D}$ printing file can be uploaded;

- 3D printing: the $3 \mathrm{D}$ printing procedure is basically automatic; depending on the size of the object, the materials, and the printer, the procedure can take from a few minutes to a few days; it must be checked, from time to time, to verify that there are no errors; in this case, due to the small specimen, it lasted on average about 30 minutes.

- Removing the printed object: In most cases, in nonindustrial $3 \mathrm{D}$ printing, the printed object can be easily removed - the printed part is separated from the work table of the $3 \mathrm{~d}$ printer.

- Further processing: after printing 27 specimens with the shape of a "ring/washer" with the same nominal dimensions and different printing parameters (the most important parameters being - printing speed $[\mathrm{mm} / \mathrm{s}]$, printing temperature $\left[{ }^{\circ} \mathrm{C}\right]$ and layer height $[\mathrm{mm}])$, they went through the processing of the final product, a process that includes manual cleaning, in order to be measured on the horizontal profile projector, Starrett Optical to determine the inside diameter, outside diameter and thickness. Table 1.

These measurements were centralized in 
Table 1. Printing parameters of the 27 specimens

\begin{tabular}{|c|c|c|c|}
\hline $\begin{array}{c}\text { Crt. } \\
\text { no. }\end{array}$ & $\begin{array}{c}\text { Velocity } \\
{[\mathbf{m m} / \mathbf{s}]}\end{array}$ & $\begin{array}{c}\text { Temperature } \\
{\left[{ }^{\circ} \mathbf{C}\right]}\end{array}$ & $\begin{array}{c}\text { Thickness } \\
{[\mathbf{m m}]}\end{array}$ \\
\hline $\mathbf{1}$ & 60 & 190 & 0,07 \\
\hline $\mathbf{2}$ & 60 & 190 & 0,1 \\
\hline $\mathbf{3}$ & 60 & 190 & 0,2 \\
\hline $\mathbf{4}$ & 60 & 195 & 0,07 \\
\hline $\mathbf{5}$ & 60 & 195 & 0,1 \\
\hline $\mathbf{6}$ & 60 & 195 & 0,2 \\
\hline $\mathbf{7}$ & 60 & 210 & 0,07 \\
\hline $\mathbf{8}$ & 60 & 210 & 0,1 \\
\hline $\mathbf{9}$ & 60 & 210 & 0,2 \\
\hline $\mathbf{1 0}$ & 80 & 190 & 0,07 \\
\hline $\mathbf{1 1}$ & 80 & 190 & 0,1 \\
\hline $\mathbf{1 2}$ & 80 & 190 & 0,2 \\
\hline $\mathbf{1 3}$ & 80 & 195 & 0,07 \\
\hline $\mathbf{1 4}$ & 80 & 195 & 0,1 \\
\hline $\mathbf{1 5}$ & 80 & 195 & 0,2 \\
\hline $\mathbf{1 6}$ & 80 & 210 & 0,07 \\
\hline $\mathbf{1 7}$ & 80 & 210 & 0,1 \\
\hline $\mathbf{1 8}$ & 80 & 210 & 0,2 \\
\hline $\mathbf{1 9}$ & 80 & 190 & 0,07 \\
\hline $\mathbf{2 0}$ & 100 & 190 & 0,1 \\
\hline $\mathbf{2 1}$ & 100 & 190 & 0,2 \\
\hline $\mathbf{2 2}$ & 100 & 195 & 0,07 \\
\hline $\mathbf{2 3}$ & 100 & 195 & 0,1 \\
\hline $\mathbf{2 4}$ & 100 & 195 & 0,2 \\
\hline $\mathbf{2 5}$ & 100 & 210 & 0,1 \\
\hline $\mathbf{2 6}$ & 100 & 210 & 0,2 \\
\hline $\mathbf{2 7}$ & 100 & 210 & \\
\hline & & & 07 \\
\hline
\end{tabular}

For all 27 specimens, the inside diameter, outside diameter, and thickness were measured three times, and then calculated:

- the average of the three measurements;

- relative error: $\left(\frac{\text { Average }- \text { Nominal value }}{\text { Nominal value }}\right) \times 100$;

- absolute error (the difference between the average of the three measurements and the nominal value);

- amplitude (the difference between the maximum value and the minimum value of the three measurements).

After calculating these parameters and processing the values obtained to identify the absolute error, relative error, and amplitude, the parameters were compared to check whether the errors in the inner diameter, outer diameter, and thickness are controllable.

The diagrams of absolute errors, relative errors, and amplitude for inner diameter, outer diameter, and thickness are represented graphically in Figures $3 \div$ 11 .

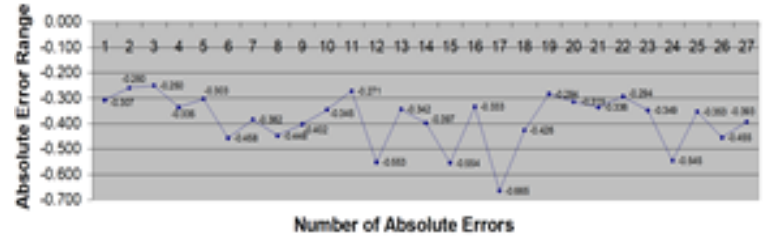

Figure 3. Diagram of absolute errors obtained for the inner diameter

Figure 3 shows that, regardless of the printing characteristic with which the specimens were printed, the absolute error of the inner diameter was always less than the nominal / desired value. $(d=\varnothing 20 \mathrm{~mm})$.

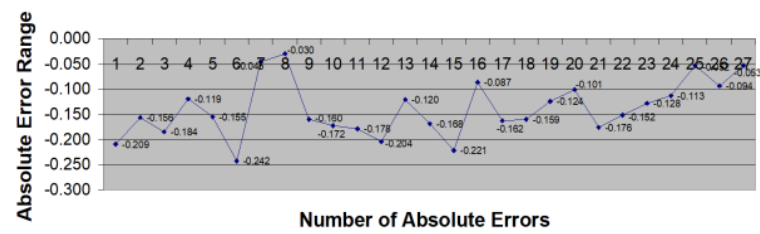

Figure 4. Diagram of absolute errors obtained for the outer diameter

Figure 4 shows that specimens 7, 8, 25, and 27, because of the chosen printing characteristics, the absolute error of the outer diameter is, as a value, close to the nominal / desired value. $(D=\varnothing 30 \mathrm{~mm})$, and the other specimens have an outer diameter smaller than the desired value.

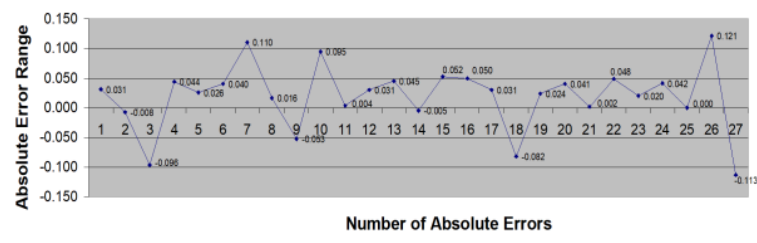

Figure 5. Diagram of absolute errors obtained for thickness

Figure 5 shows that specimen 25 has the desired thickness, specimens $2,8,11,14$, and 21 are close to the desired thickness and the other specimens have the absolute error either smaller or higher than the nominal / desired value $(\mathrm{g}=4 \mathrm{~mm})$ of thickness.

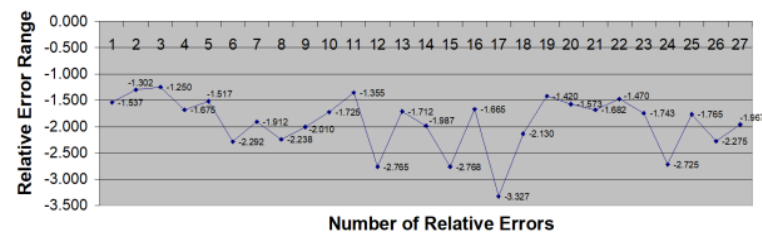

Figure 6. Diagram of relative errors obtained for the inner diameter

Figure 6 shows that, regardless of the printing characteristic with which these specimens were printed, the relative error of the inner diameter was always smaller than the nominal / desired value $(\mathrm{d}=$ Ø20 mm). 


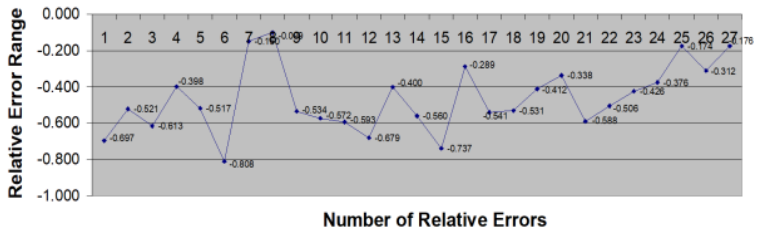

Figure 7. Diagram of relative errors obtained for the outer diameter

Figure 7 shows that specimens 7, 8, 25, and 27, because of the chosen printing characteristics, the relative error of the outer diameter is, as a value, close to the nominal / desired value $(\mathrm{D}=\varnothing 30 \mathrm{~mm})$ and the other specimens have a diameter exterior smaller than the desired value.

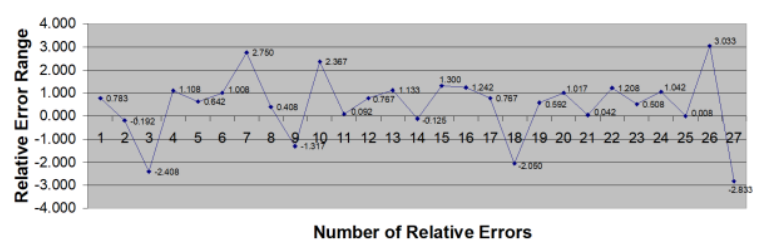

Figure 8. Diagram of relative errors obtained for thickness

Figure 8 shows that specimen 25 has the thickness closest to the desired thickness, specimens $2,11,14$, and 21 are close to the desired thickness, and the other specimens have an absolute error either lower or higher than the nominal / desired value ( $\mathrm{g}=$ $4 \mathrm{~mm}$ ) of thickness.

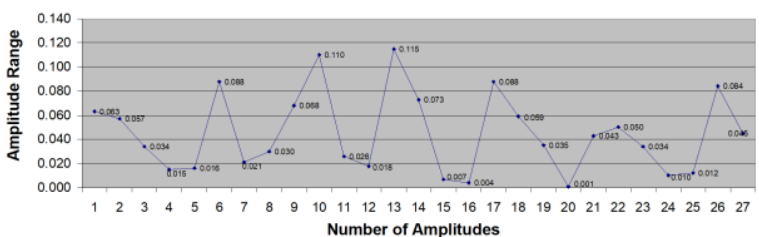

Figure 9. Diagram of the amplitudes obtained for the inner diameter

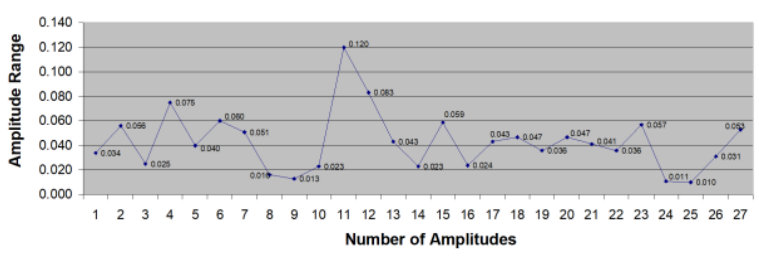

Figure 10. Diagram of the amplitudes obtained for the outer diameter

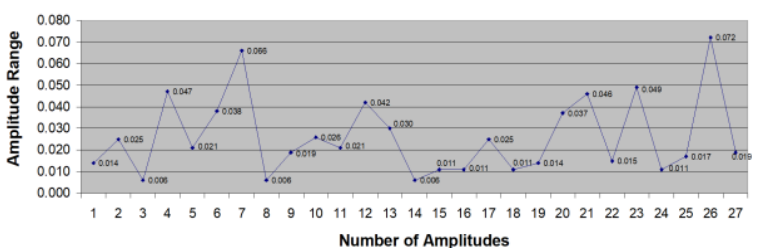

Figure 11. Diagram of amplitudes obtained for thickness

The specimens 15, 16, and 20, from Figures 9, 24 and 25 from Figure 10, and 3, 8 and 14, from Figure 11, have the amplitude nearest to zero, for which it may be said that the difference between the maximum value and the minimum of the three measurements performed for each specimen indicates that the geometric shape measured (outer diameter, inner diameter, and thickness) has errors of the order of microns.

\section{APPL YING PRINT ORRECTIONS}

Following the laboratory experiments, which consisted of 2D and 3D design of specimens, the introduction of printing parameters, printing the specimens, measuring them, and performing various mathematical calculations to verify the value of the error (respectively, possible differences from the values entered in the design stage and the values obtained after printing), it was found that a specimen can be printed with an insignificant printing error, which will result in printing a specimen with the dimensions closer to the desired dimensions.

After using a neural network, the following relative errors resulted:

- for the inner diameter - Delta_Di $=-2.9986$;

- for the outer diameter - Delta_De $=-0.5787$;

- for thickness - Delta_g $=1.6809$.

For the application of mathematical corrections, the relative error was transformed into an absolute error, like this:

$$
\frac{\text { Nominal value }_{\mathrm{i}} \times \text { Delta }_{\mathrm{i}}}{100},
$$

in which:

- Nominal value $_{i}$ represents the nominal value of the inner, outer diameter, and thickness;

- Delta $a_{i}$ - the relative errors obtained after using a neural network (Delta_Di, Delta_De și Delta_g).

Using equation (1), we obtain:

- for the inner diameter: $\frac{20 \cdot 2.9986}{100}=0.598 \mathrm{~mm}$;

- for the outer diameter: $\frac{30 \cdot 0.5787}{100}=0.170 \mathrm{~mm}$;

- for thickness: $\frac{4 \cdot 1.6809}{100}=0.067 \mathrm{~mm}$.

For relative errors with a negative value, the negative sign was changed and the value obtained was added to the absolute error with the nominal value to determine the design values.

As for the errors with positive values, the positive value was kept and it was subtracted from the nominal value. Thus, obtaining the values of the absolute error.

Therefore, the new overall dimensions of the specimen were calculated:

- for the inner diameter: $20+0.598=20.598 \mathrm{~mm}$;

- for the outer diameter: $30+0.170=30.170 \mathrm{~mm}$;

- for thickness: $4-0.067=3.933 \mathrm{~mm}$. 
As a result, it was found that, in order to obtain a washer/ring type specimen with the desired dimensions and with the littlest error possible, the specimen must have the following dimensions and parameters:

- inner diameter, $d=\varnothing 20.598 \mathrm{~mm}$;

- outer diameter, $D=\varnothing 30.170 \mathrm{~mm}$;

- thickness, $g=3.933 \mathrm{~mm}$;

- printing speed, $v=70 \mathrm{~mm} / \mathrm{s}$;

- melting temperature of the material, $T=200^{\circ} \mathrm{C}$;

- layer thickness, $g_{s}=0.15 \mathrm{~mm}$.

After designing the correct specimen, printing it, measuring it, centralizing the measurements, calculations were performed to verify its accuracy.

Table 2. Measurements obtained and their centralization for the corrected specimen

\begin{tabular}{|c|c|c|c|}
\hline $\begin{array}{c}\text { Corrected } \\
\text { Specimen }(\mathbf{C S})\end{array}$ & $\begin{array}{c}\boldsymbol{d} \\
{[\mathbf{m m}]}\end{array}$ & $\begin{array}{c}\boldsymbol{D} \\
{[\mathbf{m m}]}\end{array}$ & $\begin{array}{c}\mathbf{g} \\
{[\mathbf{m m}]}\end{array}$ \\
\hline Nominal Value & 20 & 30 & 4 \\
\hline 1 & 20,015 & 30,210 & 4,046 \\
\hline 2 & 20,038 & 30,216 & 4,047 \\
\hline 3 & 19,998 & 30,248 & 4,075 \\
\hline Average CS & 20,017 & 30,225 & 4,056 \\
\hline Absolute error CS & 0,017 & 0,225 & 0,056 \\
\hline Relative error CS & 0,085 & 0,749 & 1,400 \\
\hline Amplitude CS & 0,040 & 0,038 & 0,029 \\
\hline
\end{tabular}

\section{CONCLUSIONS}

In this scientific paper, a washer / ring specimen was printed with the desired overall dimensions that were set during the design stage $(\mathrm{d}=\varnothing 20 \mathrm{~mm}, \mathrm{D}=\varnothing 30$ $\mathrm{mm}$, and $\mathrm{g}=4 \mathrm{~mm}$ ).

Following the printing of the 27 specimens and the measurements on the horizontal profile projector, Starrett Optical, the following conclusions were obtained:

- specimen 3, printed with a speed of $60 \mathrm{~mm} / \mathrm{s}$, melted material at a temperature of $190^{\circ} \mathrm{C}$ and a layer thickness of $2 \mathrm{~mm}$, is the specimen closest to the nominal inside diameter $(\mathrm{d}=\varnothing 20 \mathrm{~mm})$, with $\mathrm{d}=$ $\varnothing 19,750 \mathrm{~mm}$

- specimen 8 , printed with a speed of $60 \mathrm{~mm} / \mathrm{s}$, melted material at a temperature of $210^{\circ} \mathrm{C}$ and a layer thickness of $1 \mathrm{~mm}$, is the specimen closest to the nominal outer diameter $(\mathrm{D}=\varnothing 30 \mathrm{~mm})$, with $\mathrm{D}=$ $\varnothing 29,970 \mathrm{~mm}$;
- specimen 25, printed with a speed of $100 \mathrm{~mm} / \mathrm{s}$, the melted material at a temperature of $210^{\circ} \mathrm{C}$ and a layer thickness of $0,07 \mathrm{~mm}$, has the desired nominal thickness ( $\mathrm{g}=4 \mathrm{~mm}$ ), having $\mathrm{g}=4,000 \mathrm{~mm}$;

- the specimen that is showing the inside diameter, the outside diameter, and the thickness with the nearest desired dimensions is specimen 3 .

For specimen 3, dimensional corrections were applied (depending on the values obtained at absolute error, relative error and amplitude of this specimen) during the design stage, afterwards to be printed with dimensional corrections and checked with the horizontal profile projector, Starrett Optical, to check that the desired dimensions have been obtained.

After applying the printing corrections, it resulted in errors that are controllable and can be reduced. In order to minimize the printing error, several features must be considered:

- shrinkage of the printed material - depending on this it is possible to add the printing error to the desired values to finally get the mark with the desired dimensions.

- geometric shape, which can play an important role in landmarks with complex geometric shapes.

- printing parameters, which can determine the dimensional accuracy of printed parts; if printed at high speed and high thickness, the accuracy and quality of the printed part may be low.

\section{REFERENCES}

[1] ***, Introduction to $3 D$ printing (Introducere $\hat{\imath}$ imprimarea 3D), 2016, https://3d-p.eu/wpcontent/uploads/2018/08/IO3 3DP-courseware_RO.pdf;

[2] ***, What is Rapid Prototyping? - Definition, Methods and Advantages, TWI, 2020, https://www.twiglobal.com/technical-knowledge/faqs/faq-manufacturing-what-israpid-prototyping;

[3] ***, Ultimaker 3 Extended 3D Printer Fully Assembled, MatterHackers, https://www.matterhackers.com/store/printer-kits/ ultimaker-3-extended-3d-printer-fully-assembled;

[4] Voxel Factory, Ultimaker 3 Extended $3 D$ Printer (Imprimante $3 D \quad$ Ultimaker 3 Extended), 2020, https://fr.voxelfactory.com/products/ultimaker-3-extended-3dprinter

[5] Filamente 3D, Everything you need to know about PLA (Polylactic Acid) (Tot ce trebuie să știți despre PLA (Acidul Polilactic)_, 2019, https://www.filamente3d.ro/blog/desprefilamente/tot-ce-trebuie-sa-stiti-despre-pla-acidul-polilactic;

[6] ***, Starrett, HE400 Horizontal Benchtop Optical Comparator, https://www.starrett.com/metrology/product-detail/ HE400;

[7] ***, StoreFront, Non-Contact, Optical Comparators, https://store.measurenow.com/optical-comparators-c46.aspx. 